\title{
EMDR in Older Adults With Posttraumatic Stress Disorder
}

\author{
Ellen Gielkens \\ Mondriaan Hospital, Heerlen, The Netherlands \\ Marja Vink \\ GERION, General Practice \& Elderly Care Medicine, VU University Medical Center, Amsterdam, The Netherlands \\ Sjacko Sobczak \\ Mondriaan Hospital, Heerlen, The Netherlands \\ Erlene Rosowsky \\ Department of Clinical Psychology, William James College, Newton, Massachusetts \\ Bas Van Alphen \\ Center of Excellence of Personality Disorders in Older Adults, Mondriaan Hospital, Heerlen, The Netherlands
}

\begin{abstract}
Recognition of posttraumatic stress disorder (PTSD) in older adults is often difficult due to its complicated presentation. Once recognized, trauma symptoms can, in accordance with (inter)national guidelines, be successfully treated with eye movement desensitization and reprocessing (EMDR) therapy. However, limited empirical research has been done on the expression and treatment of PTSD in older adults. This article explains trauma and age in the context of psychotherapy. It discusses the interaction between age and pathology and summarizes the cognitive issues related to age, PTSD, and anxiety. It provides practical suggestions for how these can be addressed in treatment. Age-related challenges related to motivation are identified with practical suggestions for addressing them. The case illustrates the necessary additions and subtractions for older adults, with clear explanations and instructions. This article points the way for future research.
\end{abstract}

Keywords: older adults; eye movement desensitization reprocessing; posttraumatic stress disorder; psychotherapy

A mong older adults in the United States, the prevalence of posttraumatic stress disorder (PTSD) ranges from $1.5 \%$ to $4 \%$ (Acierno et al., 2007). Compared to younger adults, with a prevalence rate of $6.8 \%$, PTSD seems to be less common in older adults (Kessler et al., 2005; Pietrzak, Goldstein, Southwick, \& Grant, 2011). However, prevalence rates of subclinical PTSD appear to be higher in older adults and range from $5.5 \%$ to $13.1 \%$ (Glaesmer, Gunzelmann, Braehler, Forstmeier, \& Maercker, 2010; Hauffa et al., 2011; Pietrzak, Goldstein, Southwick, \& Grant, 2012; van Zelst et al., 2003). This might well reflect that the Diagnostic and Statistical Manual of Mental Disorders (DSM)-based diagnostic criteria are poorly reflective of the presentation in older adults. As a consequence, it is suggested that lower cutoff scores on PTSD screening instruments might identify PTSD more accurately in older adults (Cook \& O'Donnell, 2005; Pietrzak et al., 2012). In the DSM5 , important changes were made to the diagnostic criteria for PTSD. It is not clear how this might influence detection in older adults. Results of the National Health and Resilience in Veterans Study showed that in U.S. veterans, the probability of PTSD and odds of psychiatric comorbidity were similar to prior findings using DSM-IV-based measures (Wisco et al., 2016). It has been pointed out that in the case of early life traumatization, avoidance and arousal symptoms are more prominent in older adults with chronic PTSD (Böttche, Kuwert, \& Knaevelsrud, 2012) while dissociation is decreased (Labinsky, Blair, \& Yehuda, 2006).

In older adults, PTSD can be revealed in different ways. PTSD may develop after exposure to an acute traumatic event, without earlier traumatic 
experiences. Data from a nationally representative sample show that older adults suffer significantly fewer potentially traumatic experiences than younger adults (Reynolds, Pietrzak, Mackenzie, Chou, \& Sareen, 2016). In some cases, being an older adult may even protect against the development of PTSD due to a lifetime of adaptive coping experiences and the accumulation of wisdom that can lessen the effects of traumatic experiences (Weintraub \& Ruskin, 1999).

Another possibility is that PTSD exists for many years due to fundamental experiences earlier in life. PTSD may become chronic. Symptoms are felt as ego-syntonic and will not be recognized by the older adults as originating from a psychiatric disorder. They have adapted their life to their complaints.

In addition, markedly adversive life events in childhood may establish a vulnerability that increases their likelihood of a delayed-onset PTSD later in life. PTSD symptoms, thus, can become reactivated by new traumatic experiences in later life or even newly activated.

In most instances, however, PTSD symptoms may be subsyndromal but then increase with age due to developmental processes of aging. The most prevalent triggers to delayed-onset PTSD were related to the onset of neurological and other disorders affecting cognition (e.g., cerebrovascular accident, dementia; Andrews, Brewin, Philpott, \& Stewart, 2007). Changes in environmental characteristics due to increased dependency may be more prevalent in older adults. Institutionalization and care dependency can trigger past trauma experiences and thereby exacerbate or elicit PTSD symptoms (Anderson, Fields, $\&$ Dobb, 2011). Furthermore, role changes, functional losses, losses of loved ones, and health problems become more prevalent. Avoidance-based coping strategies become less available or effective with advancing age (Khouzam, 2008), and PTSD may no longer be restrained.

Despite the presentation of mental health conditions in older age and attendant need for treatment, older adults are less likely than younger- and middleaged adults to receive mental health treatment by a mental health specialist (Bogner, de Vries, Maulik, \& Unützer, 2009; Tran \& Ponce, 2017). There are a number of ways to consider why the recognition and treatment of psychological problems, perhaps especially PTSD, may be challenging in the older adult population (Gielkens, van Alphen, Sobczak, \& Segal, 2014).

Psychological symptoms are difficult to recognize because older adults are often more likely to report pain or other physical complaints rather than emotional ones. Cohort features might be an important consideration. The current older old (>75 years), it is often recognized, are not used to talking about psychological issues, are very private about these, and feel shame and fear when they do discuss these feelings (Franco, 2007). They did not grow up in an area where mental health treatment was known to be available. They might not be informed or might be poorly informed about current treatment possibilities. With regard to PTSD, specifically in the case of PTSD with delayed onset, the original traumatic event occurred long ago, and its impact may be disregarded (Ladson \& Bienenfeld, 2007). It is also worth noting that PTSD was first introduced into the diagnostic nomenclature in 1980 and did not "exist," despite the presence of symptoms, at the time of the original trauma (Cook, McCarthy, \& Thorp, 2017).

PTSD can induce or further worsen somatic disorders, which determine treatment focus. Unavoidable and sustained stress can impair functioning of the hypothalamic-pituitary-adrenal axis, which is thought to result in declining resiliency in later life (Lupien, McEwen, Gunnar, \& Heim, 2009). As a result, PTSD is often related to premature biological aging and earlier mortality. PTSD is associated with a phenotype of accelerated senescence and targeted conditions known to be connected with normal aging, such as cardiovascular disease, type 2 diabetes mellitus, and dementia (Lohr et al., 2015). The impact of impairments in daily life and lowered life satisfaction is linked to PTSD and often endures decades after traumatic experiences (Fridman, Bakermans-Kranenburg, SagiSchwartz, \& Van IJzendoorn, 2011; Hiskey, Luckie, Davies, \& Brewin, 2008).

Another aspect that can complicate recognition of psychological symptoms of PTSD in old age is an increase in functional losses and stressors. Therapists or older adults themselves may think that feelings of sadness and anxiety are normal. Furthermore, these life events can trigger unprocessed past grief. In general, people with more traumatic experiences show increased coping problems in dealing with life events such as accumulated losses (Hantman \& Solomon, 2007). Healthcare professionals may focus on these life events instead of the past traumatic experiences.

All adults go through an aging process. By doing so, characteristic physical and cognitive changes appear and may impact psychological problems and inform treatment of these problems. Frequently occurring diseases of old age, such as dementia, cerebrovascular accidents, or Parkinson's disease, may cause cognitive impairment, which complicates the clinical picture. Cognitive impairment is more common in adults with 
PTSD compared with subjects exposed to trauma without PTSD (Qureshi et al., 2011). It is reported that pre-existing brain abnormalities may be a risk factor in developing PTSD (Kremen, Koenen, Afari, \& Lyons, 2012). The National Health and Resilience in Veterans Study suggests that exacerbated PTSD symptoms in late life in veterans may be associated with executive dysfunction for $10 \%$ of U.S. veterans (Mota et al., 2016). Difficulties with executive function and concentration, perhaps due to decreased possibilities in directing attention away from emotionally salient trauma-related memories, emerged as an independent determinant of aggravated PTSD symptoms (Mota et al., 2016). Cognitive deficits can also be a product of neurobiological changes caused by the PTSD itself (Samuelson, 2011). Learning disabilities, memory dysfunction, and attention deficits have been associated with PTSD (Hayes, Vanelzakker, \& Shin, 2012; Scott et al., 2015). Individuals with PTSD and anxiety tend to recall personal memories in an overly general way, with very few details (Hayes et al., 2012). This "generalization" occurs in response to cues or stimuli that are similar to those associated with the original traumatic event. Over time, these stimuli may expand and become even more generalized (Kaczkurkin et al., 2017).

Furthermore, older adults are more likely to be prescribed medication with possible side effects, synergistic effects, or iatrogenic effects. These co-occurring medical problems hamper assessment and treatment due to symptom overlap, additional symptoms, or exacerbation of symptoms.

PTSD is known to have a high rate of diagnostic comorbidity with other psychiatric diagnoses, which complicates recognition and treatment decisions. Symptoms often overlap, and substantial genetic vulnerability or shared epigenetic factors provide a possible explanation for high comorbidity rates. Especially when childhood adversities were present, negative effects on mental health do not become significantly weaker in later life (Raposo, Mackenzie, Henriksen, \& Afifi, 2014).

Approximately $80 \%$ to $90 \%$ of people with PTSD have at least one co-occurring psychiatric disorder, and $66 \%$ have two or more co-occurring psychiatric disorders (van Minnen, Zoellner, Harned, \& Mills, 2015). Pietrzak et al. (2012) confirm that PTSD and partial PTSD in a representative sample of U.S. older adults (aged 60+ years) are associated with significantly elevated odds of lifetime mood, anxiety, drug abuse, and borderline and narcissistic personality disorders. A study from Raposo et al. (2014) found that older adults who experienced childhood adversity had higher odds of having other anxiety, mood, and personality disorders in later life, in addition to PTSD.

Personality disorders appear to co-occur with PTSD. A meta-analysis to identify comorbid personality disorders across the major subtypes of anxiety disorders found that $35 \%$ of adults with PTSD also had one or more personality disorders (Friborg, Martinussen, Kaiser, Overgård, \& Rosenvinge, 2013). High comorbidity between PTSD and personality disorders may be in part explained by symptom overlap of the disorders (e.g., Borderline or Dependent personality disorder), such as difficulties in managing emotions or problems with abandonment. The impact of psychological treatment on personality disorder and PTSD is underreported in older adults. In younger adults (mean age 40 years), it was found that treating a chronic PTSD decreased most personality disorders, especially personality disorders whose symptom criteria overlapped PTSD symptoms (Markowitz et al., 2015). Personality traits, a combination between native temperament and learned coping skills, may render the individual especially vulnerable to the impact of PTSD.

\section{Psychological Treatment in Older Adults With PTSD}

Even in present times, we recognize that biases in caregivers or healthcare practitioners often affect what psychological services are offered (Knight, 2009). Instead of psychological treatment, clinicians might prescribe medications or practical forms of help, such as domestic aid or assistance with specific activities of daily living.

However, slowly but surely, psychological therapy is gaining more familiarity. To date, no evidence exists that older adults cannot benefit from psychological treatment. When providing psychological treatment to older PTSD patients, particular age-specific (cognitive) changes and related needs in the therapeutic process must be taken into account. Physical and cognitive alterations may necessitate adjustments in psychological treatment (American Psychological Association [APA], 2009). Physical problems may play a bigger role, such as becoming tired more quickly, diminished vision or hearing, and difficulties in mobility. Moreover, aging may cause cognitive challenges. In normal aging, processing speed, episodic memory, and executive function are most susceptible for decline (Deary et al., 2009). This cognitive decline influences the processing of information and can complicate comprehension and recall of therapeutic material (Hyer \& Sohnle, 2001). Multimodal 
representations of information and a clear focus on the current topic of conversation are often helpful modifications (Cook \& Niederehe, 2007; Wilkinson, 1997). According to the Psychotherapy and Older Adults Resource Guide drawn up by the APA (2009), psychotherapy in older adults sometimes needs to be adapted; context effects, cohort effects, and specific age-related challenges need to be considered (APA, 2009). Certainly, some level of knowledge about neuropsychological assessment, medical disorders, and medication is needed in order to create an appropriate treatment plan. Older adults often cannot distinguish psychological problems and are unfamiliar with the possibilities of psychological treatment. Knowledge of cohort effects can help a therapist to gain a better understanding of the patient's background and underlying beliefs that can affect treatment.

The under-reporting of traumatic events necessitates a detailed and sensitive process of recollection at the beginning of treatment. When asked supplementary questions, older adults may report psychological complaints, and it may lead to hasty and extensive memories of the trauma and greater distress and symptom expression. Sorting out physical, psychological, and cognitive influences on the older adults' functioning is an ongoing process. The social support systems and support of professional caregivers may become more important in the lives of older adults with physical and psychological problems. As a result, psychological interventions must develop from a broad-based treatment concept, including these extra-individual and environmental components.

Guidelines offer some more directions, for example, taking an active and exploring attitude when talking about psychological symptoms, paying particular attention to the connection between psychotherapy and their symptoms, being flexible in location and duration, involving caregivers in treatment, coordinating care, and collaborating with other disciplines.

In general, psychological treatment for depressive disorders has been demonstrated to be effective for older adults, especially cognitive-behavior therapy (CBT) and problem-solving therapy (Cuijpers, Karyotaki, Pot, Park, \& Reynolds, 2014). Psychological treatment (CBT, acceptance and commitment therapy, modular therapy) for anxiety disorders has also been demonstrated to be beneficial at older age (Anderson et al., 2011; Bower, Wetherell, Mon, \& Lenze, 2015; Gonçalves \& Byrne, 2012).

Over the last few decades, many treatments have been developed for treating PTSD. Trauma-focused CBT and eye movement desensitization and reprocessing (EMDR) therapy (Shapiro, 2001) are considered treatments of choice and evidence-based psychotherapies for PTSD (Forbes et al., 2010). The efficacy of these evidence-based treatments for older complex psychiatric patients (e.g., with comorbid cognitive decline and personality disorders) has not been studied (Gielkens, Sobczak, \& Van Alphen, 2016). Unfortunately, older adults are excluded from randomized controlled trials studying the effects of psychological treatments for PTSD (Dinnen, Simiola, \& Cook, 2015).

EMDR is a psychotherapeutic method that integrates and processes trauma memories by asking the individual to recall trauma-related memories while side-to-side eye movements are induced. A meta-analysis of clinical studies confirmed that EMDR therapy significantly reduces the symptoms of PTSD, depression, anxiety, and subjective distress in PTSD patients (Chen et al., 2014). Most of the studies included only younger adults. Older adults, certainly the older old, are often missing in research data. In a systematic review of treatment effects in older adults with PTSD, Dinnen et al. (2015) found that although there were mixed results and relatively few studies of treatment of PTSD in older adults with overall small sample sizes, cognitive restructuring, narrative exposure, and prolonged exposure were reported as effective. Only a few case studies reported EMDR treatment and provided preliminary evidence that EMDR appears acceptable and efficacious in older adults (71 years old [Burgmer $\&$ Heuft, 2004]; 72 years old [Hyer, 1995]; and 66 years old [Hyer \& Woods, 1998]). Furthermore, Mikhailova (2015) reported EMDR is highly effective in elderly inpatients. The study involved 26 women, aged $70-85$ years, with mild to moderate cognitive impairment and a history of psychological trauma.

\section{Adjustments in EMDR Treatment for Older Adults}

Older adults often suffer from psychological problems caused by the cumulative effect of unresolved traumatic and adverse experiences. Furthermore, physical and especially cognitive decline become more common. Intellectual and cognitive functioning seem not to hamper effective EMDR therapy in children and developmentally delayed patients (Diehle, Opmeer, Boer, Mannarino, \& Lindauer, 2015; Mevissen et al., 2012). EMDR is a relatively straightforward treatment method, easy to use, even when cognitive functioning is suboptimal. EMDR procedures may be adapted to special challenges of older adults (Vink \& Soeteman, 2015). Using 
a practice-based example, instructions on how to handle some of these challenges and how to conduct EMDR treatment in an older adult will be made. Suggestions reflect practical experience and are based on theoretical concepts. Overall, EMDR uses an eight-phase approach in which past memories, current triggers, or future situations are addressed (Shapiro, 2001). After a short case summary, these eight phases and possible challenges of work with the older adult within each phase will be discussed.

\section{Case Summary}

Mr. H., an 84-year-old Dutch widower who has lived in a residential home for 3 years, presented with mobility problems, chronic obstructive lung disease, a history of transient ischemic attacks (TIAs), and alcohol abuse. His alcohol abuse has worsened, and self-neglect was visible by his scruffy appearance. He was at considerable risk of falling. Several conversations about his decline by the general practitioner and the nurses had no effect on his behavior. Eventually, a psychologist became involved.

The investigation showed that Mr. H. has PTSD with delayed expression, complicated by excessive alcohol abuse. After a thorough clinical interview, Mr. H. reported sleep problems and severe anxiety at night due to nightmares of World War II. As a 16-year-old boy, heunderwent many traumatic experiences in a German labor camp. Ultimately, he escaped and, enduring many frightening events, he eventually returned home. Also, during the day, Mr. H. experiences terrifying war flashbacks. He uses alcohol to cope with his panic attacks, without good effect. Mr. H. is strung out and has an exaggerated startle response; an unexpected noise in the hallway or the face of a nurse can suddenly bring him back to wartime.

The course of symptoms was difficult to reconstruct. Although, there was no indication of dementia, the state of his cognitive functioning with elaborative narration style-probably related to brain damage due to alcohol abuse and TIAshad a direct impact on the difficulty of obtaining the required information. With patient explanation of his stories, it was reconstructed that PTSD was probably elicited and exacerbated by his retirement, passing away of loved ones, and loss of daily activities, combined with health problems and cognitive changes. He reported that this present meeting with the psychologist was the first time in his life he disclosed the details about his traumatic wartime experiences.
After thorough explanation about his complaints and possibilities for psychotherapy to improve them, Mr. H. was willing to try psychological treatment. Alcohol consumption was lowered to two drinks per day, distributed by nurses.

\section{EMDR Phases}

This section describes the adjustments made in the different EMDR phases to address the specific challenges of the patient's older age. The venue of the interview and treatment was the residential home. Because of his mobility problems, Mr. $\mathrm{H}$. is house bound.

Phase 1. Phase 1 in EMDR therapy with older adults is history taking. During phase 1, it will be particularly important to sort out information and engage the older patient in the therapy process. Older adults have a large amount of memories to draw upon, and often their episodic memory has declined.

Mr. H. had many past experiences to recall and report. He also has difficulty with recall and associative thinking, possibly due to cerebral damage secondary to the TIAs and alcohol abuse. His adverse early life memories were blended with nasty war images from other sources, such as Japanese military and German extermination camps, probably accumulated through war documentaries and books. He was convinced that he had experienced the events himself: "It will just bake my retinas." For EMDR treatment, the emotionality of memories is important, not the source of the memories or establishing an accurate narrative. Perhaps, in older adults, because of accumulative years, memories may be more modified compared to the original sources or may be more often incorrectly attributed to sources. Remarkably, Mr. $\mathrm{H}$. was silent for years, and once he spoke about his memories he was unstoppable in his stories about terrible war experiences. As a result, he needed clear guidance in the conversation. In this phase, it is especially important to create a feeling of trust and connection using an active and exploring attitude. The therapist must help to control the memory flow in a friendly way while also clarifying it. No one knew about his psychological demons. In a number of cases, reluctance to acknowledge taboo subjects, such as sexuality and death, are found, especially when feelings of shame or guilt are present. A therapist can help to gently address these feelings. As Mr. H. never revealed deep emotions in the presence of others, the treatment 
can help him become more familiar with this new experience and to tolerate it.

Phase 2. In phase 2, the preparation phase, psychoeducational interventions will be continued, and it will be explained how psychological problems can emerge due to traumatic life events. In addition, information about assimilation is given. When cognitive function is impaired, it may be necessary to include important caregivers to support trust and therapeutic connection.

In the case of Mr. H., there were no family members available, but nursing home personnel were informed of the treatment plan. Initially, Mr. $\mathrm{H}$. did not want psychological treatment until he realized that intervention was relatively short and exclusively directed at his nightmares, intrusions, and arousal. Concrete expectations on which symptoms could be anticipated to decrease when using EMDR can offer some treatment perspective.

Phase 3. Phase 3 is the assessment phase used to identify each target in a standardized manner. During this phase, several issues may come up in work with older adults. These problems are often related to cognitive skills. Target selection needs to consider these potential problems carefully. Sometimes a target will be easy to find, identified through clearly reported flashbacks. Sometimes this is not the case, and the therapist has to assist in determining the targets.

In the case of Mr. H., his list of horrible memories was extensive, and the therapist needed to work with him to reduce the list of workable targets. For example, a specific question would help him to select a memory to work with "which image disturbed you the most last night?" He described an image where Japanese soldiers taught German soldiers how to torture and limbs were cut off by prisoners while the soldiers stood around laughing. The therapist can suggest a negative cognition (NC; and positive cognition [PC]) based on the selected target and the symptoms reported. Target-related cognitions can fall into four domains (self-directiveness, responsibility, safety, and control). In some cases, when cognitive decline is too much, it is not possible to identify an NC (and PC), and this step will be skipped as is the case with distress and credibility levels (Subjective Units of Disturbance [SUD] and Validity of Cognition [VOC] scores). Older adults may experience difficulties in evaluating SUD and VOC levels. Sometimes it may happen that VOC is interpreted the other way around and may give rise to slowing down the procedure. Mr. H.'s
NC was in the control domain as is nearly always the case with flashbacks/nightmares. He was able to mention an SUD level of 8 at the start, after thorough education.

Phase 4. In phase 4, the desensitization phase, disturbing emotions and sensations are also measured using the SUD rating. This can be simplified if needed. For example, the therapist can ask "What do you feel at this moment?" and observe the patient carefully if he/ she cannot report the feeling. If there is any tension visible, the target is assumed not to be neutralized, and the processing has to go on. During the desensitization process, the therapist leads the patient in sets of eye movements. In older adults, eye movements must be decelerated if working memory and attention are identified as reduced. Sometimes eye movements must be replaced by taps or (ir)regular tones. Neurological conditions affecting visual or auditory perception restrict the forms of stimulation. During desensitization with older adults, it might also be necessary to adjust the speed and duration of the stimulation, for example, slowing it when mental speed is low.

For Mr. H., intervention was needed to reduce his narratives down to a one sentence target before the process progressed. Otherwise, the processing stagnated because of loss of focus. After continuing the process, his SUD levels descended between sets of eye movements from 8 to 9 to 8 and eventually to 0 . In the case of Mr. H., at this point he reported that he was too tired, and the session was ended before the installation phase. Also, at this time, he expressed doubts about continuing the therapy because of the intensity of his emotions and feeling uncertain about its helpfulness. Motivational techniques were used to keep Mr. H. in therapy. Additional education about PTSD and EMDR therapy was given, and about progress he made during one session.

Phase 5. In the installation phase (phase 5), the goal is to increase the credibility of the PC ("I am in control now") that has been identified to replace the original NC. During Mr. H.'s next session, the PC was installed without problems.

Phase 6. Phase 6 is the body scan phase during which the physical response(s) to the original target is/are checked. In the case of unresolved thoughts, residual tensions in the body are likely to rise. If so, these physical sensations are then targeted for reprocessing. When the older patient does not mention a physical sensation, but where tension is visible, the therapist may ask the patient to focus, for example, 
on the tremor, clenched fists, or furrowed forehead, and so on.

Phase 7. Phase 7, the closure phase, has the goal to ensure the person leaves at the end of each session feeling better than when the session began. In addition to the usual closure procedure, new, and often more, questions arise requiring clarifications. Sometimes the therapist can introduce questions such as "What helped you today?" or "What is valuable and what do you want to be sure to remember?" or "I think it's really brave to go back to such nasty experiences, what do you think?" for the purpose of reviewing and clarifying progress and reinforcing treatment gains. Mr. H.'s most positive feeling about himself was "I was able to talk about my traumatic experiences." With some help, he was able to formulate the positive results he learned during the session: "I am able to cope with these difficult matters, I am strong."

Phase 8. Phase 8 , the reevaluation phase, is used to open each new session. During this phase, the therapist checks in with the patient to make sure that the positive gains have been maintained between sessions. If not, then the reprocessing of the prior targets is continued. If the gains have been maintained, then new targets for treatment can be identified. Mr. H. reported that he did have nightmares but not of the treated target. A new image is selected from his most recent nightmare, and the procedure started over from phase 3.

For Mr. H., doubts about EMDR treatment arise again. Mr. H. hesitates if treatment elicits distress, and he must be motivated to schedule a follow-up appointment. Sometimes it is necessary to involve caregivers in order to motivate involvement of an older patient in EMDR therapy.

In the case of Mr. H., nurses were involved to keep him motivated in-between sessions. If the older patient is not able to reflect on his symptoms, as is necessary in phase 8 , one can question his or her support system or professional caregivers. While it is critical to keep the focus of the treatment on the target symptoms, this can be difficult due to the many stories and possible symptoms, especially from multiple reporting sources. The therapist's stance and active support of the therapeutic frame are needed to keep the therapy on course.

Follow-Up. After Mr. H. had three sessions of EMDR, his nightmares disappeared along with his distress engendered by trauma-related cues. These positive changes were maintained in a 16-month follow-up despite some decline in his physical condition.

\section{Conclusion}

The use of psychotherapy with older adults is increasing due to changing demographics, changes in service settings, and greater acceptability with rising cohorts. Nonetheless, older adults with mental disorders are less likely than younger adults to receive mental health services from mental health specialists (Bogner et al., 2009). Cohort features and characteristics are known to contribute to the underutilization of psychological treatment, as does access to appropriate care. In the case of PTSD, recognition may be complicated by under-reporting symptoms by the older adult, even though validated psychological treatment for PTSD appears to be as effective with older adults as with younger adults (Böttche et al., 2012; Cook \& O’Donnell, 2005). Comorbidity with multiple psychological and somatic diagnoses are, however, more common in older adults and can complicate the PTSD picture. Where cognitive dysfunction hampers communication, then the different stages of the standard EMDR protocol may be too difficult to undergo, but modifications can be considered, informing target selection and desensitization techniques (Amano \& Toichi, 2014). History taking by caregivers or family members may also be needed to clarify the symptoms, identify an appropriate target, and help maintain motivation. Sometimes if words cannot connect, memorabilia, such as photographs, can be used to access memories, which then can be processed.

The case of Mr. H. illustrated that PTSD symptoms were kept hidden for several dozen years, not visible for his family, nurses, or physician, until his sleeping problems, alcohol abuse, and self-neglect got out of hand. Once clinically identified, EMDR treatment was very successful in three sessions. Because of Mr. H.'s associative language use and the abundance of memories that were difficult to order, regular "talking" psychotherapy was deemed inappropriate. Motivational problems due to lack of confidence that therapy can bring about change, his physical condition, and characteristic disconnection from affect recognition indicated that he would have found engaging in cognitive-behavioral treatments too challenging, especially if these required complying with homework between sessions. An advantage of EMDR treatment is that the focus is easier to identify, and that homework is not part of the program. Another advantage is that EMDR can bring about fast results, which is especially important in older adults 
to keep them motivated and because interruptions in treatment due to health problems and situational challenges may make it difficult for them to maintain a consistent, extended therapy.

Furthermore, the positive effect of the therapy was shown to be sustained for 16 months after the treatment was discontinued. Mental health clinicians should be encouraged to consider and screen for PTSD with their older adult patients and to make inquiries into traumatic experiences and PTSD symptomatology. If identified and diagnosed with PTSD, the treatment option of EMDR could be considered.

\section{Recommendations for Future Research}

Statistical evidence for EMDR in this population is preliminary, but clinical experiences and a few case reports are encouraging and provide further support for the use of EMDR with older individuals. EMDR is applicable and efficacious in older adults as it is with younger adults. However, more research is needed to investigate the potential role of EMDR with older adults, certainly with older olds $(75+$ years), who present with high rates of comorbid diseases and heterogeneous presentation. The EMDR protocol appears to be able to be applied successfully with adjustments customized for the individual. For example, with Mr. H., adjustments were made to accommodate his cognitive limitations.

The research in this area is scant. More needs to be explored to see if there are true differences in EMDR treatment feasibility and effects based on different comorbid conditions, which are especially common in older adults with PTSD.

\section{References}

Acierno, R., Lawyer, S. R., Rheingold, A., Kilpatrick, D. G., Resnick, H. S., \& Saunders, B. E. (2007). Current psychopathology in previously assaulted older adults. Journal of Interpersonal Violence, 22(2), 250-258. http: / dx.doi.org/ $10.1177 / 0886260506295369$

Amano, T., \& Toichi, M. (2014). Effectiveness of the on-thespot-EMDR-method for the treatment of behavioural symptoms in patients with severe dementia. Journal of EMDR Practice and Research, 8(2), 50-65. http://dx.doi. org/10.1891/1933-3196.8.2.50

American Psychological Association. (2009). Psychotherapy and older adults resource guide. Retrieved from http:/ / www. apa.org/ pi / aging/resources / guides / psychotherapy.aspx.

Anderson, K. A., Fields, N. L., \& Dobb, L. A. (2011). Understanding the impact of early-life trauma in nursing home residents. Journal of Gerontological Social Work,
54(8), 755-767. http://dx.doi.org/10.1080/01634372. 2011.596917

Andreescu, C., \& Varon, D. (2015). New research on anxiety disorders in the elderly and an update on evidence-based treatments. Current Psychiatry Reports, 17(7), 53. http:/ / dx.doi.org/10.1007/s11920-015-0595-8

Andrews, B., Brewin, C. R., Philpott, R., \& Stewart, L. (2007). Delayed-onset posttraumatic stress disorder: A systematic review of the evidence. American Journal of Psychiatry, 164(9), 1319-1326. http://dx.doi.org/10. 1176/appi.ajp.2007.06091491

Bogner, H. R., de Vries, H. F., Maulik, P. K., \& Unützer, J. (2009). Mental health services use: Baltimore Epidemiologic Catchment area follow-up. The American Journal of Geriatric Psychiatry, 17(8), 706-715. http://dx.doi.org/ 10.1097/JGP.0b013e3181aad5c5

Böttche, M., Kuwert, P., \& Knaevelsrud, C. (2012). Posttraumatic stress disorder in older adults: An overview of characteristics and treatment approaches. International Journal of Geriatric Psychiatry, 27(3), 230-239. http: / / dx. doi.org/10.1002/gps.2725

Bower, E. S., Wetherell, J. L., Mon, T., \& Lenze, E. J. (2015). Treating anxiety disorders in older adults: Current treatments and future directions. Harvard Review of Psychiatry, 23(5), 329-342. http://dx.doi.org/10.1097/HRP. 0000000000000064

Burgmer, M., \& Heuft, G. (2004). Occurrence and treatment of post-traumatic stress disorder in an elderly patient after a traffic accident. International Journal of Geriatric Psychiatry, 19(2), 185-188. http://dx.doi.org/ 10.1002/gps.1047

Chen, Y. R., Hung, K. W., Tsai, J. C., Chu, H., Chung, M. H., Chen, S. R., . . .Chou, K. R. (2014). Efficacy of eye-movement desensitization and reprocessing for patients with posttraumatic-stress disorder: A meta-analysis of randomized controlled trials. PloS One, 9(8), e103676. http: / / dx.doi.org/10.1371/journal.pone.0103676

Cook, J. M., McCarthy, E., \& Thorp, S. R. (2017). Older adults with PTSD: Brief state of research and evidencebased psychotherapy case illustration. The American Journal of Geriatric Psychiatry, 25(5), 522-530. http: / dx. doi.org/10.1016/j.jagp.2016.12.016

Cook, J. M., \& Niederehe, G. (2007). Trauma in older adults. In M. J. Friedman, T. M. Keane, \& P. A. Resick (Eds.), Handbook of PTSD; science and practice (pp. 253276). New York, NY: Guilford Press.

Cook, J. M., \& O’Donnell, C. (2005). Assessment and psychological treatment of posttraumatic stress disorder in older adults. Journal of Geriatric Psychiatry and Neurology, 18(2), 61-71. http:/ / dx.doi.org/10.1177/ 0891988705276052

Cuijpers, P., Karyotaki, E., Pot, A. M., Park, M., \& Reynolds, C. F. (2014). Managing depression in older age: Psychological interventions. Maturitas, 79(2), 160-169. http: / / dx.doi.org/10.1016/j.maturitas.2014.05.027

Deary, I. J., Corley, J., Gow, A. J., Harris, S. E., Houlihan, L. M., Marioni, R. E., . . .Starr, J. M. (2009). Age-associated 
cognitive decline. British Medical Bulletin, 92, 135-152. http: / / dx.doi.org/10.1093/bmb/ldp033

Diehle, J., Opmeer, B. C., Boer, F., Mannarino, A. P., \& Lindauer, R. J. (2015). Trauma-focused cognitive behavioral therapy or eye movement desensitization and reprocessing: What works in children with posttraumatic stress symptoms? A randomized controlled trial. European Child \& Adolescent Psychiatry, 24(2), 227-236. http: / / dx.doi.org/10.1007/ s00787-014-0572-5

Dinnen, S., Simiola, V., \& Cook, J. M. (2015). Post-traumatic stress disorder in older adults: A systematic review of the psychotherapy treatment literature. Aging \& Mental Health, 19(2), 144-150. http://dx.doi.org/10.1080/ 13607863.2014.920299

Forbes, D., Creamer, M., Bisson, J. I., Cohen, J. A., Crow, B. E., Foa, E. B., . . .Ursano, R. J. (2010). A guide to guidelines for the treatment of PTSD and related conditions. Journal of Traumatic Stress, 23(5), 537-552. http: / / dx.doi. org/10.1002/jts.20565

Franco, M. (2007). Posttraumatic stress disorder and older women. Journal of Women \& Aging, 19(1-2), 103-117. http: / / dx.doi.org/10.1300/J074v19n01_07

Friborg, O., Martinussen, M., Kaiser, S., Overgård, K. T., \& Rosenvinge, J. H. (2013). Comorbidity of personality disorders in anxiety disorders: A meta-analysis of 30 years of research. Journal of Affective Disorders, 145(2), 143-155. http:// dx.doi.org/10.1016/j.jad.2012.07.004

Fridman, A., Bakermans-Kranenburg, M. J., Sagi-Schwartz, A., \& Van IJzendoorn, M. H. (2011). Coping in old age with extreme childhood trauma: Aging Holocaust survivors and their offspring facing new challenges. Aging \& Mental Health, 15(2), 232-242. http://dx.doi.org/10. $1080 / 13607863.2010 .505232$

Gielkens, E. M., Sobczak, S., \& Van Alphen, S. P. (2016). Eye movement desensitization and reprocessing therapy for personality disorders in older adults? International Psychogeriatrics, 28(10), 1751-1752. http://dx.doi.org/ $10.1017 /$ S1041610216000892

Gielkens, E. M. J., van Alphen, B., Sobczak, S., \& Segal, D. L. (2014). Brief eclectic psychotherapy for an older Dutch woman with late-onset posttraumatic stress disorder complicated by a cerebral vascular accident. Clinical Case Studies, 13(5), 423-435. http:/ / dx.doi.org/ $10.1177 / 1534650113517933$

Glaesmer, H., Gunzelmann, T., Braehler, E., Forstmeier, S., \& Maercker, A. (2010). Traumatic experiences and post-traumatic stress disorder among elderly Germans: Results of a representative population-based survey. International Psychogeriatrics, 22(4), 661-670. http://dx. doi.org/10.1017/S104161021000027X

Gonçalves, D. C., \& Byrne, G. J. (2012). Interventions for generalized anxiety disorder in older adults: A systematic review and meta-analysis. Journal of Anxiety Disorders, 26(1), 1-11. http://dx.doi.org/10.1016/j.janxdis. 2011.08.010

Hantman, S., \& Solomon, Z. (2007). Recurrent trauma: Holocaust survivors cope with aging and cancer. Social
Psychiatry and Psychiatric Epidemiology, 42(5), 396-402. http: / / dx.doi.org/10.1007/ s00127-007-0177-0

Hauffa, R., Rief, W., Brähler, E., Martin, A., Mewes, R., \& Glaesmer, H. (2011). Lifetime traumatic experiences and posttraumatic stress disorder in the German population. The Journal of Nervous and Mental Disease, 199(12), 934-939. http://dx.doi.org/10.1097/ NMD. ob013e3182392c0d

Hayes, J. P., Vanelzakker, M. B., \& Shin, L. M. (2012). Emotion and cognition interactions in PTSD: A review of neurocognitive and neuroimaging studies. Frontiers in Integrative Neuroscience, 6(89), 89. http://dx.doi.org/10. 3389 / fnint.2012.00089

Hiskey, S., Luckie, M., Davies, S., \& Brewin, C. R. (2008). The phenomenology of reactivated trauma memories in older adults: A preliminary study. Aging \& Mental Health, 12(4), 494-498. http://dx.doi.org/10.1080/ 13607860802224367

Hyer, L. (1995). Use of EMDR in a "dementing” PTSD survivor. Clinical Gerontologist, 116, 70-73.

Hyer, L., \& Woods, M. G. (1998). Phenomenolgy and treatment of trauma in later life. In V. M. Follette, J. I. Ruzek, \& F. A. Abueg (Eds.), Guilford. New York, NY: Cognitive Behavioural Therapies for Trauma.

Hyer, L. A., \& Sohnle, S. (2001). Trauma among older people: Issues and treatment. Philadelphia, PA: Routledge.

Kaczkurkin, A. N., Burton, P. C., Chazin, S. M., Manbeck, A. B., Espensen-Sturges, T., Cooper, S. E., . . .Lissek, S. (2017). Neural substrates of overgeneralized conditioned fear in PTSD. American Journal of Psychiatry, 174(2), 125-134. http://dx.doi.org/10.1176/appi.ajp. 2016.15121549

Kessler, R. C., Berglund, P., Demler, O., Jin, R., Merikangas, K. R., \& Walters, E. E. (2005). Lifetime prevalence and age-of-onset distributions of DSM-IV disorders in the national comorbidity survey replication. Archives of General Psychiatry, 62(6), 593-602. http:/ / dx.doi.org/10. 1001 / archpsyc.62.6.593

Khouzam, H. R. (2008). Posttraumatic stress disorder in aging. Postgraduate Medicine, 120(3), 122-129. http: / / dx. doi.org/10.3810/pgm.2008.09.1913

Knight, B. G. (2009). Clinical supervision for psychotherapy with older adults. In N. A. Pachana, K. Laidlaw, \& B. G. Knight (Eds.), Casebook of clinical geropsychology: International perspectives on practice (pp. 107-118). New York, NY: Oxford University Press.

Kremen, W. S., Koenen, K. C., Afari, N., \& Lyons, M. J. (2012). Twin studies of posttraumatic stress disorder: Differentiating vulnerability factors from sequelae. Neuropharmacology, 62(2), 647-653. http://dx.doi.org/ 10.1016/j.neuropharm.2011.03.012

Labinsky, E., Blair, W., \& Yehuda, R. (2006). Longitudinal assessment of dissociation in Holocaust survivors with and without PTSD and non-exposed aged Jewish adults. Annals of the New York Academy of Sciences, 1071(1), 459-462. http://dx.doi.org/10.1196/annals. 1364.042 
Ladson, D., \& Bienenfeld, D. (2007). Delayed reaction to trauma in an aging woman. Psychiatry, 4(6), 46-50.

Lohr, J. B., Palmer, B. W., Eidt, C. A., Aailaboyina, S., Mausbach, B. T., Wolkowitz, O. M., . . .Jeste, D. V. (2015). Is post traumatic stress disorder associated with premature senescence? A review of the literature. The American Journal of Geriatric Psychiatry, 23(7), 709-725. http: / / dx. doi.org/10.1016/j.jagp.2015.04.001

Lupien, S. J., McEwen, B. S., Gunnar, M. R., \& Heim, C. (2009). Effects of stress throughout the lifespan on the brain, behaviour and cognition. Nature Reviews Neuroscience, 10(6), 434-445. http://dx.doi.org/10.1038/ nrn2639

Markowitz, J. C., Petkova, E., Biyanova, T., Ding, K., Suh, E. J., \& Neria, Y. (2015). Exploring personality diagnosis stability following acute psychotherapy for chronic posttraumatic stress disorder. Depression and Anxiety, 32(12), 919-926. http: / / dx.doi.org/10.1002/ da.22436

Mevissen, L., Lievegoed, R., Seubert, A., \& De Jongh, A. (2012). Treatment of PTSD in people with severe intellectual disabilities: A case series. Developmental Neurorehabilitation, 15(3), 223-232. http://dx.doi.org/10.3109/ 17518423.2011 .654283

Mikhailova, E. (2015). Application of EMDR in the treatment of older people with a history of psychical trauma. European Psychiatry, 30(1), 851. http://dx.doi.org/10. 1016/S0924-9338(15)30664-7

Mota, N., Tsai, J., Kirwin, P. D., Harpaz-Rotem, I., Krystal, J. H., Southwick, S. M., \& Pietrzak, R. H. (2016). Latelife exacerbation of PTSD symptoms in US veterans: Results from the National Health and Resilience in Veterans Study. The Journal of Clinical Psychiatry, 77(3), 348-354.

Pietrzak, R. H., Goldstein, R. B., Southwick, S. M., \& Grant, B. F. (2011). Prevalence and Axis I comorbidity of full and partial posttraumatic stress disorder in the United States: Results from wave 2 of the national epidemiologic survey on alcohol and related conditions. Journal of Anxiety Disorders, 25(3), 456-465. http://dx.doi.org/ $10.1016 /$ j.janxdis.2010.11.010

Pietrzak, R. H., Goldstein, R. B., Southwick, S. M., \& Grant, B. F. (2012). Psychiatric comorbidity of full and partial Posttraumatic Stress Disorder among older adults in the United States: Results wave 2 of the National Epidemiologic Survey on Alcohol and Related Conditions. The American Journal of Geriatric Psychiatry, 20(5), 380-390. http:/ / dx.doi.org/10.1097/ JGP.0b013e31820d92e7

Qureshi, S. U., Long, M. E., Bradshaw, M. R., Pyne, J. M., Magruder, K. M., Kimbrell, T., . . Kunik, M. E. (2011). Does PTSD impair cognition beyond the effect of trauma? Journal of Neuropsychiatry, 23(1), 16-28. http: / / dx.doi.org/ 10.1176/appi.neuropsych.23.1.16

Raposo, S. M., Mackenzie, C. S., Henriksen, C. A., \& Afifi, T. O. (2014). Time does not heal all wounds: Older adults who experienced childhood adversities have higher odds of mood, anxiety, and personality disorders.
The American Journal of Geriatric Psychiatry, 22(11), 12411250. http: / / dx.doi.org/10.1016/j.jagp.2013.04.009

Reynolds, K., Pietrzak, R. H., Mackenzie, C. S., Chou, K. L., \& Sareen, J. (2016). Post-traumatic stress disorder across the adult lifespan: Findings from a nationally representative survey. The American Journal of Geriatric Psychiatry, 24(1), 81-93. http://dx.doi.org/10.1016/j.jagp.2015.11. 001

Samuelson, K. W. (2011). Posttraumatic stress disorder and declarative memory functioning: A review. Dialogues in Clinical Neuroscience, 13(3), 346-351.

Scott, J. C., Matt, G. E., Wrocklage, K. M., Crnich, C., Jordan, J., Southwick, S. M., . . Schweinsburg, B. C. (2015). A quantitative meta-analysis of neurocognitive functioning in posttraumatic stress disorder. Psychological Bulletin, 141(1), 105-140. http://dx.doi.org/10. 1037 / a0038039

Shapiro, F. (2001). Eye movement desensitization and reprocessing, basic principles, protocols and procedures (2nd ed.). New York, NY: Guilford Press.

Tran, L. D., \& Ponce, N. A. (2017). Who gets needed mental health care? Use of mental health services among adults with mental health need in California. Californian Journal of Health Promotion, 15(1), 36-45.

van Minnen, A., Zoellner, L. A., Harned, M. S., \& Mills, K. (2015). Changes in comorbid conditions after prolonged exposure for PTSD: A literature review. Current Psychiatry Reports, 17(3), 549. http://dx.doi.org/10.1007/ s11920-015-0549-1

van Zelst, W. H., de Beurs, E., Beekman, A. T. F., Deeg, D. J. H., \& van Dyck, R. (2003). Prevalence and risk factors of posttraumatic stress disorder in older adults. Psychotherapy and Psychosomatics, 72(6), 333-342. http://dx. doi.org/10.1159/000073030

Vink, M., \& Soeteman, W. (2015). EMDR bij ouderen. In H. J. Oppenheim, H. Hornsveld, E. Ten Broeke, \& A. De Jongh (Eds.), Praktijkboek EMDR deel II. Amsterdam, Nederland: H.J. Oppenheim, H. Hornsveld, E. ten Broeke en A. de Jongh, en Pearson Assessment.

Weintraub, D., \& Ruskin, P. E. (1999). Posttraumatic stress disorder in the elderly: A review. Harvard Review of Psychiatry, 7(3), 144-152. http://dx.doi.org/10.3109/ hrp.7.3.144

Wilkinson, P. (1997). Cognitive therapy with elderly people. Age and Ageing, 26(1), 53-58. http:/ / dx.doi.org/10.1093/ ageing/26.1.53

Wisco, B. E., Marx, B. P., Miller, M. W., Wolf, E. J., Mota, N. P., Krystal, J. H., . . Pietrzak, R. H. (2016). Probable posttraumatic stressdisorder in the US veteran population according to DSM-5: Results from the National Health and Resilience in Veterans Study. The Journal of Clinical Psychiatry, 77(11), 1503-1510.

Correspondence regarding this article should be directed to Ellen Gielkens, Psychologist, Psychologist, Mondriaan Hospital, Heerlen, 6401 CX, The Netherlands. E-mail: e. gielkens@mondriaan.eu 